\title{
Polimiyalji Romatika Tanılı Hastada Bilateral Pubik Ramus Yetersizlik Kırı̆̆ı
}

\author{
Bilateral Pubic Ramus Insufficiency Fracture in Patient with \\ Diagnosed Polymyalgia Rheumatica
}

Hamza Sucuoğlu, Hidayet Sarı, Kerem Gün, Murat Uludağ, Hasan Battal, Halil Koyuncu

istanbul Üniversitesi Cerrahpaşa Tıp Fakültesi, Fiziksel Tıp ve Rehabilitasyon Anabilim Dalı, İstanbul, Türkiye

\section{Özet}

Sıklıkla gözden kaçabilen ve tanı konulması zor olan pubik ramus yetersizlik kırıkları genellikle postmenopozal yaşlı kadınlarda görülmektedir. Bel, kalça ve kasık ağıısı şikayetleri ile başvuran hastalarda tanının gecikmesi, konservatif tedavisi mümkünken gereksiz invazif girişimler yapılmasına neden olmaktadır. Bu amaçla kullanılabilecek kemik sintigrafisi ve bilgisayarlı tomografi incelemeleri oldukça duyarlı tanı araçlarıdır. Osteoporoz, kortikosteroid kullanımı gibi kırık oluşumu açısından risk faktörlerine sahip yaşlı hastalarda, pubik yetersizlik kırıklarının doğru tanı ve tedavisi için klinik şüphe önem taşımaktadır. Biz de bu açıdan polimiyalji romatikaya bağlı kortikosteroid kullanan, osteoporozlu yaşlı bir kadın hastada gelişen bilateral pubik ramus yetersizlik kırığının tanı ve tedavisini literatür eşliğinde sunuyoruz. (Türk Osteoporoz Dergisi 2012;18:24-6)

Anahtar kelimeler: Polimiyalji Romatika, Pubik Ramus Yetersizlik Kırığı, Konservatif Tedavi

\section{Summary}

Pubic ramus insufficiency fractures, which are often overlooked and difficult to diagnose, are usually seen in postmenopausal elderly women. While treatment with conservative methods is possible, delays in diagnosis for patients with waist, hip and groin pain complaints may result in unnecessary invasive procedures. Bone scintigraphy and computer tomography are very sensitive diagnostic tools that can be used for this purpose. Elderly patients with osteoporosis and who use corticosteroids have higher risk factors for the occurence of such fractures. Therefore, in these patients, clinical suspicion is important for accurate diagnosis and treatment of pubic ramus insufficiency fractures. Consequently, along with the literature, we present a case of diagnosis and treatment of pubic ramus insufficiency fractures development in an elderly woman with osteoporosis who uses corticosteroids due to polymyalgia rheumatica. (Turkish Journal of Osteoporosis 2012;18:24-6)

Key words: Polymyalgia Rheumatica, Pubic Ramus Insufficiency Fracture, Conservative Treatment

\section{Giriş}

Stres kırıkları sıklıkla yaşlı postmenopozal kadınlarda, elastik direnci azalmış anormal kemiğe normal veya düşük enerjili fizyolojik bir stres uygulandığında oluşur. Pelvik yetersizlik kırıkları en sık pubik ramusta ardından sakrumda ve daha az sıklıkta asetabulumda görülür. (1) Tanı konulması zor olan, sıklıkla gözden kaçabilen, özellikle bel, kalça ve kasık ağrısıyla başvuran yaşlı kadın hastalarda, pubik yetersizlik kırıklarının doğru tanı ve tedavisi için klinik şüphe önem taşımaktadır. Biz de bu düşünceyle polimiyalji romatika (PMR) tanısıyla kortikosteroid kullanan ve osteoporozu olan pubik ramus yetersizlik kırığı tanısı koyduğumuz yaşlı postmenopozal kadın hastamızın klinik ve radyolojik bulgularını, tanı ve tedavi yöntemlerini sunmayı amaçladık.

\section{Olgu}

80 yaşında kadın hasta, 2 ay önce oturduğu yerden ayağa kalkarken kalça üzerine düşme sonrası gelişen bel, kalça ve kasık ağrıları nedeniyle polikliniğimize başvurdu. 1 yıldır romatoloji kliniğinde polimiyalji romatika tanısıyla sistemik kortikosteroid tedavisi alıyormuş. Bu şikâyetlerle başvurduğu merkezlerde PMR'ye bağlı kalça ağıları olarak değerlendirilmiş ve kortikosteroid dozu artırımış. Hastanın ağrılarının daha da artması üzerine tarafımıza başvurusunda yapılan muayenesinde, bilateral kalça hareketleri kısıtlı ve ağrılı, FABERE, FADIR 
testleri pozitif bulundu. Basmakla simfizis pubis çevresinde belirgin hassasiyet vardı. Hasta zorlukla, topallayarak ve yakınlarının desteği ile yürüyebiliyordu. Kalça ve kasık ağrısının ayırıcı tanısında inflamatuar eklem hastalıkları, septik artrit, kalça ekleminin osteonekrozu, primer veya metastatik tümörleri ekarte edebilmek açısından yapılan laboratuar değerlendirmesinde tam kan sayımı, RF ve protein elektroforezi normal sınırlardaydı. Biyokimyasal incelemede serumda kalsiyum (Ca): 9,75 (N: 8,4-10,5 mg/dl), fosfor (P): 3,9 (N: 2,3-4,7 mg/dl), 25-OH vit D: 25,7 (N: $20>\mu \mathrm{g} / \mathrm{l}), \mathrm{PTH}: 70$ (12-72 pg/mL), ALP: 115 (N: 40-150 u/l), TSH: 3,46 (N: 0,4-4,2 $\mathrm{mlU} / \mathrm{l})$, sT4: 0,87 (N: 0,7-1,9 ng/dl), Sedimentasyon: $50 \mathrm{~mm} / \mathrm{saat}$, CRP: $3.28 \mathrm{mg} / \mathrm{l}(\mathrm{N}$ : <5 mg/l) olarak ölçüldü. Kemik mineral yoğunluğu ölçümü (DEXA) ise T skoru; Femur boynu:-3,1, Femur total: -2,7, L1-L4:-3,5 olarak tespit edildi. PMR tanılı, 1 yıldır sistemik kortikosteroid kullanımı olan ve osteoporoz tespit edilen yaşlı bir kadın hasta olması sebebiyle kalçada kırık olabileceği şüphesiyle pelvis anteroposterior (A/P) grafi çektirildi. Grafi sonucunda, bilateral superior ve inferior pubik ramusda kırık hattı ve skleroze düzensiz alanlar görüldü (Resim 1). Bunun üzerine daha ayrıntılı, net görüntü elde edebilmek ve varsa sakrum kırığını da görebilmek için üç boyutlu pelvis bilgisayarlı tomografisi (BT) çektirildi. BT sonucunda pelviste inferior ve superior pubik ramusun posteriorlarında bilateral yetmezlik kırıkları ve protrüzyo asetabuli tespit edildi (Resim 2). Tedavide steroid olmayan analjezikler ve osteoporoz için nazal kalsitonin, kalsiyum ve D vitamini başlandı. PMR için kullanılan kortikosteroid tedavisi doz azaltılarak kesildi. Yatak istirahatı, yürüteç ve bastonla yük vermenin azaltılması önerildi. Hastanın ağrıları azaldıktan sonra tedaviye, hafif düzeyde eklem hareket açıklığı ve izometrik kuvvetlendirme egzersizleri eklendi. Hastanın 1 yıllık takibi sürecinde 4 kez yapılan kontrolleri sonucunda, bel, kalça ve kasıklardaki ağrılarının geçtiği ve kalça hareketlerindeki kısıtılığın azaldığı tespit edildi. Hastamız yürüteç veya baston kullanmadan yardımsız yürüyebilir ve evde günlük yaşam aktivitelerini bağımsız yapabilir hale geldi.

\section{Tartışma ve Sonuç}

Stres kırıkları dayanıksızlık ve yetersizlik kırıkları olarak iki gruptur. Dayanıksızlık kırıkları normal kemiğe yüksek şiddette stres uygulandığında, yetersizlik kırıkları ise elastik direnci azalmış anormal kemiğe normal veya düşük enerjili fizyolojik bir stres

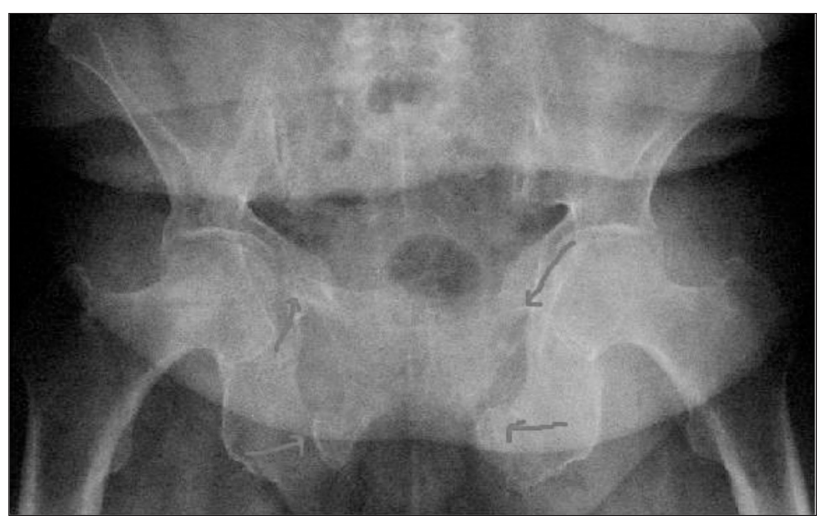

Resim 1. Superior ve inferior pubik ramuslarda bilateral yetersizlik kırık hatları uygulandığında oluşur (1). Yetersizlik kırıkları sıklıkla yaşıı postmenopozal kadınlarda görülmektedir (2). Başlıca risk faktörleri; osteoporoz, osteomalazi, hiperparatiroidizm, pelvik radyasyon uygulaması, kortikosteroid tedavisi, flor tedavisi, diabetes mellitus, Paget hastalığı gibi durumlardır (2-6). Soubrier ve ark. (7) yetersizlik kırığı olan 60 hastanın yarısında osteoporoz, altısında flor tedavisi, beşinde kortikosteroid tedavisi, diğer beş hastada romatoid artrit ve dört hastada osteomalazi vardı. Bizim hastamız ise PMR tanısıyla 1 yıldır kortikosteroid tedavisini alan osteoporozlu yaşlı bir kadın hastaydı. Yetersizlik kırığı için olası diğer risk faktörleri ise mevcut değildi. Bu hastalarda genellikle kırık öncesinde basit bir düşme öyküsü vardır (8). Taillandier ve ark. (9) pelvik yetersizlik kırığı olan 60 olgu ile yaptıkları çalışmada hastaların \%86,6'sında küçük bir düşme öyküsü bulmuşlardır. Bizim olgumuzda da öncesinde küçük bir düşme öyküsü vardı. Yetersizlik kırığı insidansının \%1-5 arasında değiştiği tahmin edilmektedir (1). Pubik kemiğin (parasimfizyal ve pubik ramus) kırıkları ile sakrum kırıkları arasında güçlü bir ilişki mevcuttur $(5,10)$. Soubrier ve ark. (7) yetersizlik kırığı olan 60 hastanın 91 kırığının \%30,7'sini (28/91) pelvik kuşakta, \%29,6'sını (27/91) sakrumda, \%16,5'i (15/91) tibiada ve \%9,9'u (9/91) femur boynunda bulmuşlardır. 8 hastada ise pelvik kuşak kırıkları ile sakrum kırıklarını ilişkili bulmuşlardır.

Pubik ramusta yetersizlik kırığı olan hastalar bel, kalça ve kasıklarda mekanik karakterli ağrı şikâyetleri ile başvurabilirler (2). Muayenede kasıkta hassasiyet ve kalça hareketlerinde ağıı ve kısıtlıık bulunur. Fakat fizik muayene bulguları genellikle tanı koydurucu değildir (3). Tanıda direkt radyografiler ilk başvurulan yöntemdir. Yetersizlik kırıklarının tanısında direkt radyografilerin değerlendirilmesi osteoporoz ve gaz gölgesi gibi nedenlere bağlı olarak her zaman mümkün olmayabilir. $(2,7,10)$. Direkt grafiler, bu hastaların tanısında düşük duyarlılığa sahip olduğundan tanı konulamayan durumlarda kemik sintigrafisi ve bilgisayarlı tomografi oldukça duyarlı tanı araçlarıdır (1). Bilgisayarlı tomografide pubik yetersizlik kırıkları genellikle etrafında kallus dokusunun eşlik ettiği lineer kırık hattı şeklinde görülür (1). Yetersizlik kırıkları için yapılan bir

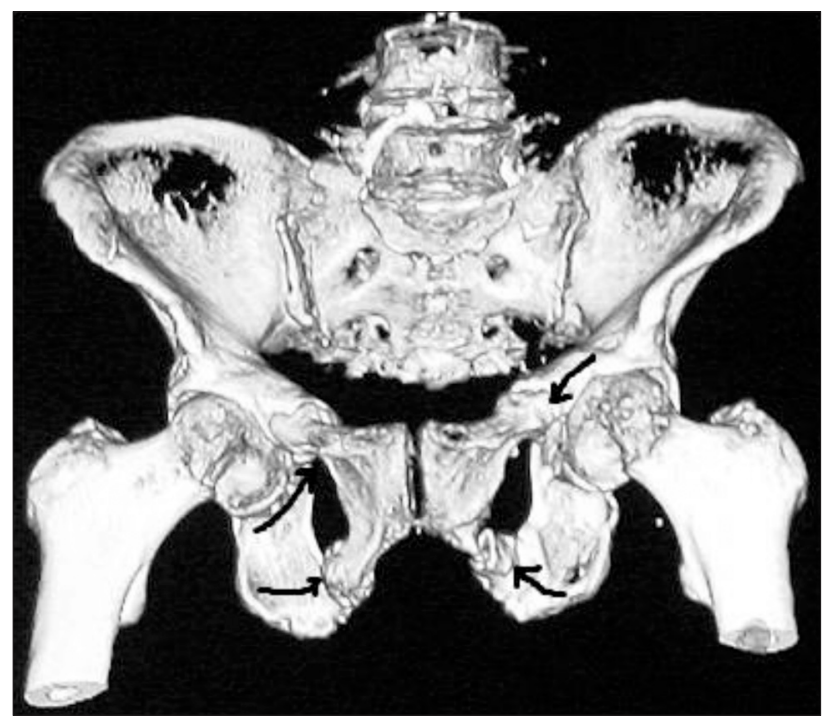

Resim 2. Üç boyutlu pelvis BT: Pelviste inferior ve superior pubik ramusun posteriorlarında bilateral yetersizlik kırıkları ve protrüzyo asetabuli 
çalışmada hastaların \%65'inde direkt radyografilerde, \%87,5'inde sintigrafide, \%98,1'inde ise bilgisayarlı tomografide kırık hattı görülmüştür (7). Bizim olgumuzda ise pelvis grafisinde bilateral superior ve inferior pubik ramusda kırık hattı görülmekle birlikte daha net görüntü elde edebilmek ve varsa sakrum kırığını da görebilmek açısından üç boyutlu pelvis tomografisi çektirildi. BT'de pelviste inferior ve superior pubik ramusun posteriorlarında bilateral yetersizlik kırıkları ve protrüzyo asetabuli görüldü, sakrum kırığı ise tespit edilmedi.

Pubis yetersizlik kırıkları yaşlılarda ve yukarıda saydığımız risk grubundaki kalça ve kasık ağrısı ile başvuran hastalarda tedavi edilebilir bir durum olması nedeniyle önemlidir. Bu hastaların erken tanısı ve doğru tedavi edilebilmesi için klinik şüphe önem kazanmaktadır (2). Pubik yetersizlik kırıkları tanısı zor konan ve sıklıkla gözden kaçabilen bir durum olduğundan yanlış ve gecikmeli tanılara rastlanmaktadır. Bu da yanlış tedavilere ve invazif girişimlere neden olabilmektedir. Hastamızda da buna benzer bir durum yaşanmış, mekanik karakterli kalça ve kasık ağılarının PMR'ye bağlı olduğu düşünülerek yanlış tanı konulmuş ve tedavinin gecikmesine, hatalı yapılmasına neden olmuştur. Yetersizlik kırıklarının tedavisi ağrı kontrolünün sağlanması, yatak istirahati, yük vermenin azaltılması, ağrılar azaldıktan sonra ise yardımcı cihazlarla yürüme ve kuvvetlendirme egzersizlerini içeren konservatif tedavi yöntemlerinin uygulanması ve osteomalazi, osteoporoz gibi risk faktörlerinin tedavisidir (2). Bizim hastamızda da osteoporoz için kalsitonin, kalsiyum, D vitamini replasmanı başlandı. Kortikosteroid tedavisi doz azaltılarak sonlandırıldı.

Ağrı tedavisi için basit analjezikler, steroid olmayan analjezikler ve zayıf opioidler kullanılabilir. Fizik tedavi yöntemleri de ağrı kontrolünde etkili olabilir (3). Kalsitonin kullanımı osteoporozu olan hastalarda analjezik etkisi nedeni ile tercih edilebilir. Sakral yetersizlik kırığı olan bir hastada subkutan 100 ıÜ/gün dozunda kalsitonin kullanımı sonrası ağrıda azalma sağlamış ve erken mobilizasyona olumlu katkısı olduğu bildirilmiştir (11). Pubik yetersizlik kırığı olan hastalarda fonksiyonel durumun iyileştirilmesi için erken dönemde rehabilitasyona başlanması, yürüteç, baston gibi yardımcı yürüme cihazlarının kullanılması ve bu tedavilerin tüm aşamalarında hastanın yakın gözlem ve takip altında tutulması önem taşımaktadır (3). Hastanın ağrıları azaldığında yardımcı yürüme cihazları ile erken dönemde yürütülmeye başlanması ve hafif ağırlıklarla kuvvetlendirme egzersizlerine geçilmesi rehabilitasyonun önemli bir parçasını oluşturmaktadır $(1,3)$. Olgumuzda ilk etapta yük vermenin azaltılması ve istirahat uygulaması sonrası ağıların azalması ile birlikte yürüme ve hafif kuvvetlendirme egzersizlerini içeren rehabilitasyon programına devam edildi.
Osteoporozla ilişkisi olan proksimal femur kırıkları sonrası eskiden kendi kendine yeten hastaların \%25-75'inde kendine yeterlilik kaybı olmaktadır. Aksine, pelvik kırıklar genelde iyi huylu kabul edilir ve bu hastalarda yaklaşık 4 ile 6 aylık bir sürede klinik iyileşme sağlanmaktadır $(1,9)$. Morbidite riski düşük olmakla birlikte belirgin fonksiyonel yetersizliğe neden olabildiği bildirilmektedir (9). Bu açıdan çeşitli çalışmalarda yeterli analjezik tedavi ve erken dönemde rehabilitasyonun başlanmasının önemine dikkat çekilmektedir $(9,12)$. Bizim hastamızda da analjezik tedavi ve erken dönemde başlanan rehabilitasyon programı ile yaklaşık 6 ay sonra kendi kendine yeterlilik düzeyini tekrar kazandı ve günlük yaşam aktivitelerini yapabilir hale geldi. Sonuç: Pubik yetersizlik kırıkları, bel, kalça ve kasıklarda ağıı, yürümede zorluk şikâyeti ile başvuran; osteoporoz ve kortikosteroid kullanımı gibi risk faktörleri bulunan ve düşme öyküsü olan postmenopozal, yaşlı kadınlarda akla getirilmelidir. Gözden kaçabilen pubik yetersizlik kırıklarının başarılı tedavisi için klinik şüphe ve doğru tanı araçlarını kullanmak önem taşımaktadır. Bu amaçla kullanılabilecek kemik sintigrafisi ve bilgisayarlı tomografi oldukça duyarlı yöntemlerdir. Tedavide analjezik ilaçlar, osteoporoz tedavisi, yatak istirahati ve yük vermenin azaltılması temel yaklaşımlardır.

\section{Kaynaklar}

1. Nacır B, Çakıt BD, Koç B, Saraçoğlu M, Erdem HR. Osteomalazili bir hastada süperior ve inferior pubik ramusun yetersizlik kırığı: Olgu sunumu. Osteoporoz Dünyası 2010;16:44-8.

2. Peh WC. Clinics in diagnostic imaging (60). Singapore Med J 2001;42:183-6.

3. Balaban B, Yaşar E, Tan AK, Kalyon TA. Sakral yetersizlik kırı̆̆ı: Olgu sunumu ve literatür derlemesi. Romatizma 2005;20:33-37.

4. Lourie $H$. Spontaneous osteoporotic fracture of the sacrum. An unrecognized syndrome of the elderly. JAMA 1982;248:715-7.

5. Cooper KL, Beabout JW, Swee RG. Insufficiency fractures of the sacrum. Radiology 1985;156:15-20.

6. Daffner RH, Pavlov H. Stress fractures: current concepts. Am J Roentgenol 1992;159:245-52.

7. Soubrier M, Dubost J-J, Boisgard S, Sauverzie B, Gaillard P, Michel JL, et al. Insufficiency fracture. A survey of 60 cases and review of the literature. Joint Bone Spine 2003;70:209-18.

8. Breuil V, Roux $\mathrm{CH}$, Testa J, Albert C, Chassang M, Brocq O, et al. Outcome of osteoporotic pelvic fractures: an underestimated severity. Survey of 60 cases. Joint Bone Spine 2008;75:585-8.

9. Taillandier J, Langue F, Alemanni M, Taillandier-Heriche E. Mortality and functional outcomes of pelvic insufficiency fractures in older patients. Joint Bone Spine 2003;70:287-9.

10. White JH, Hague C, Nicolaou S, Gee R, Marchinkow LO, Munk PL. Imaging of sacral fractures. Clinical Radiology 2003;58:914-21.

11. Paker N, Tekdos. Sacral Insufficiency Fracture: Case Report. Türk Fiz Tıp Rehab Derg 2006;52:129-31.

12. Hussain A, Paris HJ, Choukairi F, Lewis MW. Insufficiency fracture of the pubic ramus: An isolated injury? Injury Extra 2007;38:241-4. 